\title{
Intrathecal meperidine reduces intraoperative shivering during transurethral prostatectomy in elderly patients
}

\author{
Duk-Hee Chun ${ }^{1}$, Hae Keum Kil ${ }^{2}$, Hyun-Joo Kim ${ }^{3}$ Chunghyun Park ${ }^{1}$, and Kum-Hee Chung ${ }^{1}$ \\ Department of Anesthesiology and Pain Medicine, ${ }^{1} \mathrm{CHA}$ Bundang Medical Center, CHA University, Seongnam, ${ }^{2}$ Anesthesia and Pain \\ Research Institute, Yonsei Univeristy College of Medicine, ${ }^{3}$ Yonsei University College of Medicine, Seoul, Korea
}

Background: Shivering is a frequent event during the perioperative period. We performed a prospective, randomized, double-blind study to determine whether intrathecal meperidine $(0.2 \mathrm{mg} / \mathrm{kg})$ decreases the incidence and intensity of shivering after spinal anesthesia for transurethral operations.

Methods: Fifty patients scheduled for elective transurethral resection operations under spinal anesthesia were randomly allocated to two groups. Spinal anesthesia consisted of $0.5 \%$ hyperbaric bupivacaine $8 \mathrm{mg}$ and, mperidine $(0.2 \mathrm{mg} / \mathrm{kg}$ ) (meperidine group) or, normal saline (saline group). Data collection, including sensory block level (by pinprick), blood pressure, heart rate, sublingual temperature, incidence and intensity of shivering, pruritus, nausea, and vomiting was performed at 10 minute intervals.

Results: The incidence and intensity of shivering was significantly less in the meperidine group than saline group $(\mathrm{P}=0.012$ and $\mathrm{P}=0.008$, for incidence and intensity, respectively). However, pruritus was more common in the meperidine group compared with the saline group ( $16 \%$ vs. $0 \%, \mathrm{P}<0.05)$.

Conclusions: The addition of meperidine $0.2 \mathrm{mg} / \mathrm{kg}$ to intrathecal bupivacaine lowers the incidence and severity of shivering during transurethral prostatectomy in elderly patients. (Korean J Anesthesiol 2010; 59: 389-393)

Key Words: Anesthesia, Meperidine, Shivering, Spinal.

\section{Introduction}

Shivering is a relatively frequent complication associated with spinal, and general anesthesia that can be distressing to patients and can occasionally result in deleterious sequelae $[1,2]$. Hypothermia-induced shivering increases total body oxygen consumption and may cause hypoxemia [3]. Poorly tolerant patients, with compromised cardiopulmonary systems, are presumably at greatest risk because shivering increases cardiac output and causes tachycardia [2-5]. Most patients undergoing transurethral resection of the prostate (TURP) are elderly and have co-morbid cardiac or pulmonary diseases. This is thus a concern as TURP has been associated with perioperative hypothermia and subsequent shivering. In addition, the TURP

Received: May 26, 2010. Revised: 1st, June 24, 2010; 2nd, July 13, 2010. Accepted: July 14, 2010.

Corresponding author: Hae Keum Kil, M.D., Department of Anesthesiology and Pain Medicine, Anesthesia and Pain Research Institute, Yonsei University College of Medicine, 250, Sungsan-no, Seodaemun-gu, Seoul 120-752, Korea. Tel: 82-2-2228-2414, Fax: 82-2-312-7185, E-mail: hkkil@yuhs.ac

(c) This is an open-access article distributed under the terms of the Creative Commons Attribution Non-Commercial License (http:// creativecommons.org/licenses/by-nc/3.0/), which permits unrestricted non-commercial use, distribution, and reproduction in any medium, provided the original work is properly cited. 
procedure requires a large amount of irrigating fluids, which may further increase the incidence of shivering.

Many drugs have been used to treat perianesthetic shivering, including meperidine, clonidine, ketanserin, and doxapram; and most studies have concluded that meperidine is considerably more effective in treating shivering than others [68]. Adding a small dose of meperidine to the intrathecal mixture during spinal anesthesia reduces the incidence and severity of shivering and is known to retain characteristics of the sensory block $[1,9,10]$. However, these studies were mainly done on obstetrical populations undergoing cesarean delivery.

Davoudi and colleagues [11] have reported a study on TURP patients using $5 \%$ lidocaine with meperidine $15 \mathrm{mg}$ to reduce shivering.

The study presented here was designed to determine the effect of intrathecal meperidine after spinal anesthesia with $0.5 \%$ bupivacaine on shivering in elderly patients, less than 80 years of age, receiving TURP.

\section{Materials and Methods}

After approval from the Institutional Review Board, written informed consent was obtained from 50 patients scheduled to undergo TURP. Patients refusing to receive spinal anesthesia, those older than 80 years of age, and those with the presence of coagulopathy, spinal deformity, or a history of spine surgery were excluded. The trial was prospective, randomized, and double blind with parallel groups. Patients were allocated into a meperidine group (Group $\mathrm{M}, \mathrm{n}=25$ ) or a saline group (Group $\mathrm{S}, \mathrm{n}=25$ ) by a computer-generated randomization method. To detect a $50 \%$ reduction of shivering incidence, a sample size of 18 patients per group was required (with an $\alpha=0.05, \beta=0.2$, and a power of $80 \%$ ). We determined that 25 patients would be included in each group with a power of $90 \%$.

The drug mixture was prepared by an anesthesiologist and conveyed to the practitioner who was blinded in the study. The drug mixture was plain $0.5 \%$ bupivacaine and preservativefree meperidine hydrochloride $5 \%$ in group $M$ and plain bupivacaine $(0.5 \%, 8 \mathrm{mg})$ with an equivalent volume of normal saline in group $\mathrm{S}$.

Before the spinal anesthesia, patients were placed under standard monitoring and received intravenous (IV) lactated Ringer's solution 300-500 ml. Spinal puncture was performed in the lateral decubitus position using a 25-gauge Quincke needle at the L3-4 or L4-5 interspace with a midline approach. Drugs were administered after free flow of cerebrospinal fluid was visible. Patients were then placed supine and the level of the sensory block was assessed using the pin-prick test with a $22 \mathrm{G}$ hypothermic needle every minute during the first 10 minutes, and then every 10 minutes for 50 minutes. The time at the end of the intrathecal injection was defined as T0.

The incidence and intensity of shivering were evaluated at each 10 minute interval and blood pressure (BP), heart rate, $\mathrm{SpO}_{2}$, sublingual temperature, and amount of ephedrine administered were also evaluated at each interval. Pruritus or nausea and vomiting were noted by asking patients during investigation. Shivering was graded using the scale described by Crossley and Mahajan [12] ( $0=$ no shivering; $1=$ piloerection or peripheral vaso-constriction but no visible shivering; 2 = muscular activity in only one muscle group; 3 = muscular activity in more than one muscle group but not generalized shivering; 4 = shivering involving the whole body). Sublingual temperature was monitored using an oral temperature probe with a monitor (Infinity Delta Monitor En, Draeger Medical Systems, Inc., Quarry Road Telford, PA, USA) simultaneously.

Hypotension was defined as a decrease in systolic BP $30 \%$ less than baseline and bradycardia was defined as less than 40 beats per minute. It was planned to treat hypotension with $4 \mathrm{mg}$ of ephedrine IV, bradycardia with $0.5 \mathrm{mg}$ of atropine IV, severe nausea or vomiting with ondansetrone $2 \mathrm{mg}$ IV. All IV fluid and irrigating fluid used during operation was stored at room temperature. The operating room temperature was maintained at $24^{\circ} \mathrm{C}$ using a room temperature control system.

During the operation, the patient's upper body was covered with a simple cotton blanket. When patients complained of coldness or shivering, they were actively warmed by forcedwarm air (Warming Unit-Model 505, Bair Hugger ${ }^{\mathrm{TM}}$, Augustine Medical Inc., Eden Prairie, MN, USA). When the shivering grade was greater than 3 , meperidine $(0.2 \mathrm{mg} / \mathrm{kg})$ was injected IV.

Statistical analyses were performed with PASW ${ }^{\circledR}$ Statistics (version 17, SPSS Inc, Chicago, IL, USA). Demographic data, operation time, and amount of irrigation fluid by groups were compared using the Student's t-test. The incidence of shivering, pruritus, and nausea and vomiting were analyzed with the chi-square test, and intensity of shivering was analyzed with the Mann-Whitney U test. A P value of $<0.05$ was considered statistically significant.

\section{Results}

All patients completed the study. There was no difference between groups with respect to demographic data, age, height, or weight (Table 1). Of the 50 patients, 44 had comorbid diseases (Table 2). The incidence of shivering was less in Group $\mathrm{M}$ compared with Group S ( $1 / 25$ vs. $8 / 25, \mathrm{P}=0.012)$. The average shivering intensity was 1 in Group $\mathrm{M}$ and 2.5 (range, $1-4)$ in Group S (= 0.008). In Group M, pruritus was noted in four patients. No pruritus was noted in patients in Group S. There were no significant differences between groups with respect to level of sensory block, duration of operation, or 
amount of irrigation fluid needed. No significant correlation was shown between these values and the incidence of shivering in both groups (Table 3). Mean arterial pressure, heart rates, and sublingual temperature showed no differences between groups for each time interval (Fig. 1 and 2).

\section{Discussion}

Shivering profoundly increases oxygen consumption (by 200$500 \%$ ) and carbon dioxide production and decreases mixed venous oxygen saturation $[3,4]$. In a survey by Macario et al.

Table 1. Patient Demographics

\begin{tabular}{lcc}
\hline \multicolumn{1}{c}{ Characteristics } & Group M $(\mathrm{n}=25)$ & Group S $(\mathrm{n}=25)$ \\
\hline Age $(\mathrm{yr})$ & $67.3 \pm 7.4$ & $65.8 \pm 7.8$ \\
Height $(\mathrm{cm})$ & $167.3 \pm 7.8$ & $166.3 \pm 6.2$ \\
Weight $(\mathrm{kg})$ & $66.5 \pm 10.1$ & $64.5 \pm 9.8$ \\
BSA $\left(\mathrm{m}^{2}\right)$ & $1.7 \pm 0.2$ & $1.7 \pm 0.1$ \\
\hline
\end{tabular}

Values are mean \pm SD. Group M: meperidine group, Group S: saline (control) group, BSA: body surface area.

Table 2. Combined Diseases

\begin{tabular}{lc}
\hline & No. of patients \\
\hline HTN & $17(34 \%)$ \\
DM & $7(14 \%)$ \\
HTN with DM & $10(20 \%)$ \\
CAOD & 3 \\
COPD & 2 \\
Arrythmia & 2 \\
Miscellaneous & 3 \\
No combined diseases & 6 \\
Total & 50 \\
\hline
\end{tabular}

Values in number of patients (\%). HTN: hypertension, DM: diabetes mellitus, CAOD: coronary artery occlusive disease, COPD: chronic obstructive pulmonary disease.

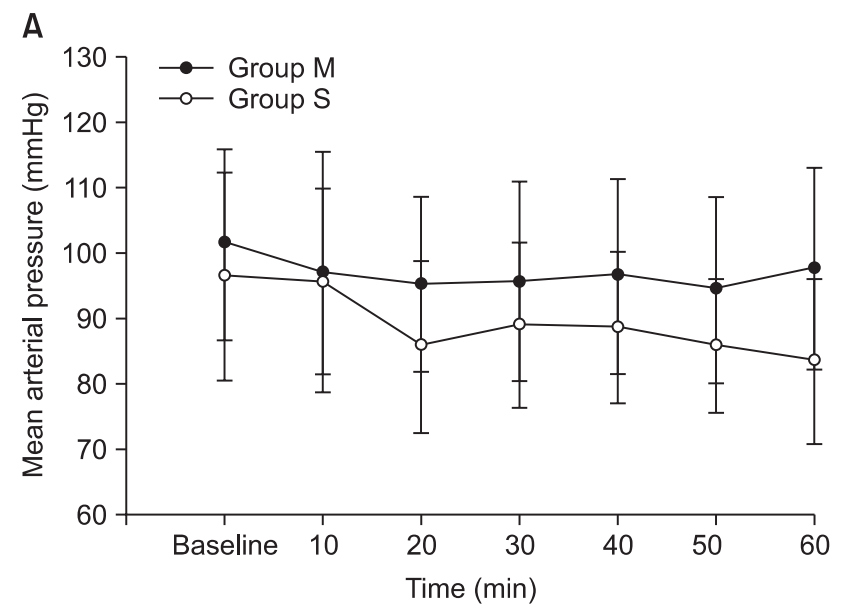

[13], many anesthesiologists scoredperioperative shivering as a moderately important outcome to avoid discussing the issue of the importance of preventing this complication. This

Table 3. Patient Characteristics

\begin{tabular}{lcc}
\hline & Group M & Group S \\
\hline Number of patients & 25 & 25 \\
Block level & T11 (T8-12) & T11 (T8-12) \\
Hypotension/Bradycardia & 2 & 1 \\
Shivering & & \\
$\quad$ Incidence & $1(4 \%)$ & $8(32 \%)^{*}$ \\
$\quad$ Intensity & 1 & $2.5(1-4)^{*}$ \\
Pruritus & 4 & $0 *$ \\
Nausea and vomiting & 0 & 0 \\
Duration of operation (min) & $47.2 \pm 15.2$ & $45.2 \pm 12.6$ \\
Irrigation fluid (ml/kg/min) & $7.78 \pm 5.10$ & $7.80 \pm 5.05$ \\
Fluid intake (ml/min) & $6.54 \pm 0.25$ & $6.81 \pm 0.24$ \\
\hline
\end{tabular}

Values are mean \pm SD or in number of patients (\%). Sensory block level and shivering intensity were expressed as median value. *Statistically significant at $\mathrm{P}<0.05$.

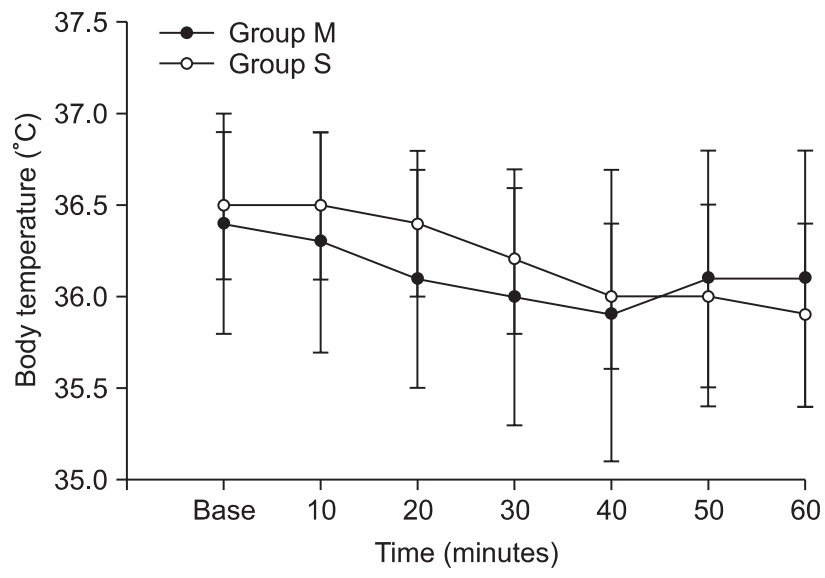

Fig. 2. Body temperature changes during the 60 minutes after spinal anesthesia.

B

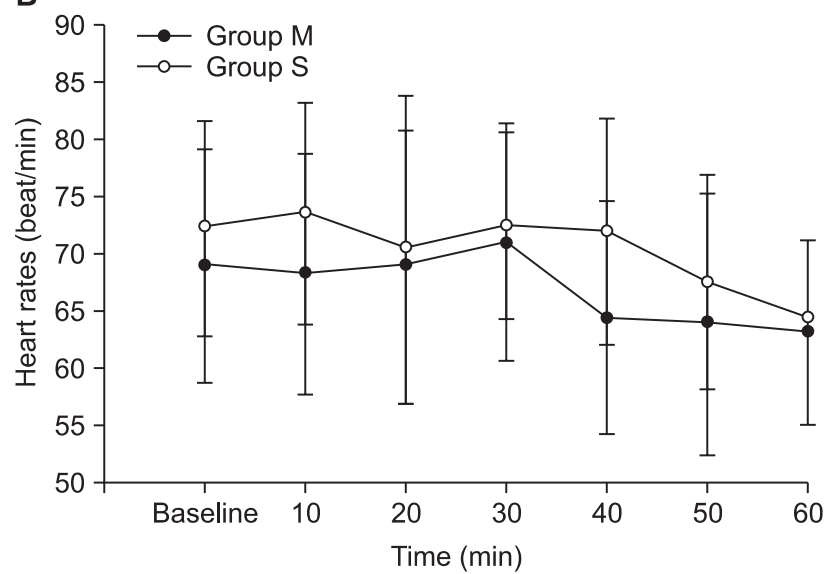

Fig. 1. Mean arterial pressure changes (A) and heart rates changes (B) during the 60 minutes after spinal anesthesia. 
suggests that most anesthesiologists do consider shivering to be a relative medical problem. However, there are a limited number of studies on shivering prevention for elderly patients undergoing TURP using additive intrathecal opioids $[11,14]$.

Although the age-related impairment of thermoregulatory function and decrease in muscle mass usually results in a low incidence of shivering in elderly patients, it has been reported to be as high as $68.5 \%$ in some procedures and there is a wide variation in incidence rates $[14,15]$. In this study, $32 \%$ of the control group showed intraoperative shivering graded between 1 and 4 . This result was similar to the result of the study by Kararmaz et al. (30\%) [15].

Three major factors contribute to core hypothermia during regional anesthesia: heat loss to the environment, inhibition of central thermoregulatory control, and redistribution of body heat [16-19]. When the body is exposed to a cold environment, the body temperature drops, and it worsens when cold IV fluid or blood is administered without warming [20-22]. Large amounts of irrigating fluids during transurethral surgery triggers even further decreases in body temperature [23,24]. In this study, we used IV and irrigating fluids at room temperature and the mean amount of fluids used was similar in the two groups. The body temperature was gradually dropped by time in both groups. At 60 minutes, the mean temperature drop was $0.4^{\circ} \mathrm{C}$ in Group $\mathrm{M}$ and $0.6^{\circ} \mathrm{C}$ in Group S. However, there were no significant differences between the two groups by time. These results are very similar to the result of a study by Davoudi et al. [11], who reported a less than $0.5^{\circ} \mathrm{C}$ decrease in body temperature during the 60 -minute study period, and that patients did not experience shivering when meperidine $15 \mathrm{mg}$ was added to $75 \mathrm{mg}$ hyperbaric lidocaine $5 \%$.

However, Davoudi et al. [11] measured axillary temperature using a mercury thermometer. Although one limitation of our study was measuring sublingual temperature instead of core temperature of tympanic membrane, sublingual and axillary temperatures are thought to reflect core temperature with reasonable accuracy $[25,26]$. It has been reported, though, that axillary temperature does not correlate well with perioperative shivering [12], and that the sublingual temperature reflects changes in body temperature better than the axillary temperature. Therefore, even though a similar trend was observed between the study of Davoudi et al. [11] and our study on body temperature, it might be difficult to regard these changes in body temperature were the same. Also, difference in local anesthetics, higher sensory block levels, and differences in the temperature of IVfluids between the Davoudi et al.'s study and our study could have influenced body temperature differently and it would be difficult correlate the two studies.

The amount of irrigating fluid used during the operation is also an important factor regarding changes in body tempe- rature, but Davoudi et al. [11] did not compare the amount of IV or irrigating fluid between groups and did not suggest the relationship of these factors with the shivering frequency. Our results showed no differences between the incidence of shivering compared to the duration of operation or the amount of IV fluid or irrigating fluids used.

The autonomic thermoregulatory responses to cold are shivering and vasoconstriction. Normally, upon exposure to cold stress, the cutaneous vasculature constricts to reduce heat loss, metabolic heat production increases, and shivering begins in an effort to maintain core body temperature. Spinal anesthesia alters autonomic thermoregulatory responses by significantly decreasing the thresholds for vasoconstriction and shivering [17]. Shivering during spinal anesthesia is thought to occur due to a loss of thermoregulatory vasoconstriction and a loss of heat by heat redistribution from core to peripheral parts of the body. However, the decrease in core body temperature is not remarkable when compared with general anesthesia because spinal anesthesia causes only redistribution of heat in the lower half of the body $[17,18]$.

Regardless of its cause, shivering has the undesirable effects of markedly increasing oxygen consumption and carbon dioxide production and decreasing mixed venous oxygen saturation [3]. Cardiac output and minute ventilation, as well as mean $\mathrm{BP}$, increase to compensate for this [2]. If these compensatory mechanisms fail, then hypoxemia may occur. These effects are often poorly tolerated by patients with limited cardiac or pulmonary reserve. Often patients who receive TURP are elderly and already at high risk for developing serious complications when hypothermia or shivering develops. Therefore, shivering prevention is more important than treatment in these patients. Adding a small amount of meperidine during spinal anesthesia may aid high risk patients from developing shivering.

In treating shivering, meperidine is much more effective than equipotent doses of other $\mu$-opioid agonists, such as fentanyl, alfentanil, sufentanil, or morphine $[27,28]$. The anti-shivering property of meperidine is not fully understood. Several studies have suggested that the anti-shivering effect of meperidine is mediated by $\kappa$-opioid receptor agonist activity $[7,8,29]$. Also meperidine decreases the shivering threshold almost twice as much as the vasconstriction threshold and this reduction in the shivering threshold appears to underlie the antishivering effect of meperidine [30]. Only 1 out of 25 patients (4\%) in the meperidine group showed shivering vs $8(32 \%)$ in the saline group in this study.

Potential side effects of meperidine such as nausea, vomiting, pruritus and hypotension must also be considered when administering meperidine [31]. We used $0.2 \mathrm{mg} / \mathrm{kg}$ of meperidine because other studies (mainly Cesarean section) reported 0.2 $\mathrm{mg} / \mathrm{kg}$ of intrathecal meperidine was effective in preventing 
shivering. In this study, $16 \%$ of the meperidine group developed pruritus and none of them had nausea or vomiting. Davoudi's study, which used $15 \mathrm{mg}$ of meperidine for all experimental patients, reported a $10 \%$ incidence rate of nausea or vomiting while none of the experimental group developed shivering. Therefore, further studies are needed to find out whether side effects of intrathecal opioid differ in elderly patients.

In conclusion, we believe that the addition of meperidine ( 0.2 $\mathrm{mg} / \mathrm{kg}$ ) to bupivacaine for spinal anesthesia during TURP in elderly patients reduces the incidence and intensity of shivering associated with spinal anesthesia. High risk patients may benefit more from intrathecal meperidine.

\section{References}

1. Roy JD, Girard M, Drolet P. Intrathecal meperidine decreases shivering during cesarean delivery under spinal anesthesia. Anesth Analg 2004; 98: 230-4.

2. Eberhart LH, Döderlein F, Eisenhardt G, Kranke P, Sessler DI, Torossian A, et al. Independent risk factors for postoperative shivering. Anesth Analg 2005; 101: 1849-57.

3. De Witte J, Sessler DI. Perioperative shivering: physiology and pharmacology. Anesthesiology 2002; 96: 467-84.

4. Macintyre PE, Pavlin EG, Dwersteg JF. Effect of meperidine on oxygen consumption, carbon dioxide production, and respiratory gas exchange in postanesthesia shivering. Anesth Analg 1987; 66: 751-5.

5. Tsai YC, Chu KS. A comparison of tramadol, amitriptyline, and meperidine for postepidural anesthetic shivering in parturients. Anesth Analg 2001; 93: 1288-92.

6. Kranke P, Eberhart LH, Roewer N, Tramèr MR. Pharmacological treatment of postoperative shivering: a quantitative systematic review of randomized controlled trials. Anesth Analg 2002; 94: 45360.

7. Alfonsi P, Hongnat JM, Lebrault C, Chauvin M. The effects of pethidine, fentanyl and lignocaine on postanaesthetic shivering. Anaesthesia 1995; 50: 214-7.

8. Wang JJ, Ho ST, Lee SC, Liu YC. A comparison among nalbuphine, meperidine, and placebo for treating postanesthetic shivering. Anesth Analg 1999; 88: 686-9.

9. Chen JC, Hsu SW, Hu LH, Hong YJ, Tsai PS, Lin TC, et al. Intrathecal meperidine attenuates shivering induced by spinal anesthesia. Ma Zui Xue Za Zhi 1993; 31: 19-24.

10. Hong JY, Lee IH. Comparison of the effects of intrathecal morphine and pethidine on shivering after Caesarean delivery under combined-spinal epidural anaesthesia. Anaesthesia 2005; 60: 116872.

11. Davoudi M, Mousavi-Bahar SH, Farhanchi A. Intrathecal meperidine for prevention of shivering during transurethral resection of prostate. Urol J 2007; 4: 212-6.

12. Crossley AW, Mahajan RP. The intensity of postoperative shivering is unrelated to axillary temperature. Anaesthesia 1994; 49: 205-7.

13. Macario A, Weinger M, Truong P, Lee M. Which clinical anesthesia outcomes are both common and important to avoid? The perspect- ive of a panel of expert anesthesiologists. Anesth Analg 1999; 88: 1085-91.

14. Chow TC, Cho PH. The influence of small dose intrathecal fentanyl on shivering during transurethral resection of prostate under spinal anesthesia. Acta Anaesthesiol Sin 1994; 32: 165-70.

15. Kararmaz A, Kaya S, Turhanoglu S, Ozyilmaz MA. Low-dose bupivacaine-fentanyl spinal anaesthesia for transurethral prostatectomy. Anaesthesia 2003; 58: 526-30.

16. Matsukawa T, Sessler DI, Christensen R, Ozaki M, Schroeder M. Heat flow and distribution during epidural anesthesia. Anesthesiology 1995; 83: 961-7.

17. Kurz A, Sessler DI, Schroeder M, Kurz M. Thermoregulatory response thresholds during spinal anesthesia. Anesth Analg 1993; 77: 721-6.

18. Ozaki M, Kurz A, Sessler DI, Lenhardt R, Schroeder M, Moayeri A, et al. Thermoregulatory thresholds during epidural and spinal anesthesia. Anesthesiology 1994; 81: 282-8.

19. Leslie K, Sessler DI. Reduction in the shivering threshold is proportional to spinal block height. Anesthesiology 1996; 84: 132731.

20. Ahn SW, Kim TH. The effects of warming intravenous fluids, sensory block level, and skin temperature on postanesthetic shivering during spinal anesthesia. Korean J Anesthesiol 1999; 37: 787-92.

21. Jaffe JS, McCullough TC, Harkaway RC, Ginsberg PC. Effects of irrigation fluid temperature on core body temperature during transurethral resection of the prostate. Urology 2001; 57: 1078-81.

22. Moore SS, Green CR, Wang FL, Pandit SK, Hurd WW. The role of irrigation in the development of hypothermia during laparoscopic surgery. Am J Obstet Gynecol 1997; 176: 598-602.

23. Allen TD. Body temperature changes during prostatic resection as related to the temperature of the irrigating solution. J Urol 1973; 110: 433-5.

24. Carpenter AA. Hypothermia during transurethral resection of prostate. Urology 1984; 23: 122-4.

25. Bissonnette B, Sessler DI, LaFlamme P. Intraoperative temperature monitoring sites in infants and children and the effect of inspired gas warming on esophageal temperature. Anesth Analg 1989; 69: 192-6.

26. Cork RC, Vaughan RW, Humphrey LS. Precision and accuracy of intraoperative temperature monitoring. Anesth Analg 1983; 62: 211-4.

27. Degroot DW, Kenney WL. Impaired defense of core temperature in aged humans during mild cold stress. Am J Physiol Regul Integr Comp Physiol 2007; 292: R103-8.

28. Alfonsi P, Sessler DI, Du Manoir B, Levron JC, Le Moing JP, Chauvin $M$. The effects of meperidine and sufentanil on the shivering threshold in postoperative patients. Anesthesiology 1998; 89: 43-8.

29. Kurz M, Belani KG, Sessler DI, Kurz A, Larson MD, Schroeder M, et al. Naloxone, meperidine, and shivering. Anesthesiology 1993; 79: 1193-201.

30. Kurz A, Ikeda T, Sessler DI, Larson MD, Bjorksten AR, Dechert M, et al. Meperidine decreases the shivering threshold twice as much as the vasoconstriction threshold. Anesthesiology 1997; 86: 1046-54.

31. Booth JV, Lindsay DR, Olufolabi AJ, El-Moalem HE, Penning DH, Reynolds JD. Subarachnoid meperidine (Pethidine) causes significant nausea and vomiting during labor. The Duke Women's Anesthesia Research Group. Anesthesiology 2000; 93: 418-21. 